\title{
Serum of obstructive sleep apnea patients impairs human coronary endothelial cell migration
}

Michal Hoffmann ${ }^{1}$, Jacek Wolf ${ }^{1}$, Anna Szyndler ${ }^{1}$, Prachi Singh², Virend K. Somers ${ }^{2}$, Krzysztof Narkiewicz ${ }^{1}$

${ }^{1}$ Department of Hypertension and Diabetology, Medical University of Gdansk, Gdansk, Poland

${ }^{2}$ Division of Cardiovascular Diseases, Department of Internal Medicine, Mayo Clinic College of Medicine, Rochester, Minnesota, USA

Submitted: 16 May 2015

Accepted: 12 August 2015

Arch Med Sci 2017; 13, 1: 223-227

DOI: 10.5114 /aoms.2015.56490

Copyright (C) 2016 Termedia \& Banach

\author{
Corresponding author: \\ Michat Hoffmann MD, PhD \\ Department of Hypertension \\ and Diabetology \\ Medical University of Gdansk \\ 7 C Dębinki St \\ 80-952 Gdansk, Poland \\ Phone: +48583492527 \\ Fax: +48 583492601 \\ E-mail: michalhoffmann@ \\ gumed.edu.pl
}

\begin{abstract}
Introduction: Endothelial cell migration and proliferation play an important role in the growth and development of new blood vessels and endothelium healing. This process occurs in response to injury, inflammation and immune reactions. Dysfunction of the endothelium may play a significant role in development and progression of cardiovascular disease related to sleep-disordered breathing. The aim of our study was to evaluate the chemo-attractant activity of serum from obstructive sleep apnea (OSA) and normal subjects on coronary artery endothelial cell migration.

Material and methods: We studied 12 severe OSA patients, free of other co-morbidities and on no treatment, along with 12 age-, body mass index, and gender matched healthy controls. Blood was collected at three time points: at 21:00 before sleep, at 6:00 after waking from sleep, and at 11:00 (after $5 \mathrm{~h}$ of normal daytime activity). Serum chemo-attractant activity for human coronary endothelial cells was assessed using a colorimetric cell migration assay kit.

Results: In healthy subjects, serum chemo-attractant activity peaked in the morning after waking from sleep $(p=0.02)$. This early morning increase was blunted in severe OSA subjects, in whom chemo-attractant activity was weaker than in normal controls $(p=0.02)$, and did not change significantly at the different time-points ( $p<0.001 \mathrm{vs.} \mathrm{controls).}$

Conclusions: Chemo-attractant activity of the serum from OSA patients is lower compared to serum from healthy subjects, especially in the morning. Altered chemo-attractant serum activity may conceivably contribute to the impairment of endothelial function in obstructive sleep apnea patients.
\end{abstract}

Key words: coronary endothelial cell migration, serum chemo-attractant activity, hypoxia, inflammation, obstructive sleep apnea.

\section{Introduction}

Sleep, both physiological and disturbed, significantly influences the cardiac and vascular system through direct and indirect actions on neural circulatory control [1, 2], coagulation [3], and endothelial function $[4,5]$. Compared to wakefulness, normal sleep decreases sympathetic activity, heart rate, vascular tone and blood pressure. In healthy subjects, endothelial function, measured as flow mediated vasodilation, is reported to be diminished in the morning directly after waking, in 
comparison with evening and late-morning measurements [5].

There is increasing evidence linking inflammation and oxidative stress to development and progression of cardiovascular disease [6-8]. Among others, the hallmarks of recurrent obstructive sleep apnea (OSA) episodes are intermittent hypoxia events, and arousals from sleep. These stimuli inevitably result in an increased sympathetic drive, hypoxemia-reoxygenation with oxidative stress, and progression of systemic inflammation, all of which are regarded to be important contributions to cardiovascular pathophysiology in OSA [9-13]. In comparison with the non-OSA healthy population, where the cardiovascular events peak around the time of awakening between 6-12 am $[14,15]$, cardiovascular events in OSA are most likely to occur at night [16].

The endothelium is a key regulator of blood flow, vascular resistance, inflammatory responses and coagulation. While a number of the studies link OSA and endothelial dysfunction [17-20], the mechanistic bias for this association is not well understood.

Endothelial cell migration (EM) helps maintain a healthy endothelium via healing, re-endothelization after endothelium injury (for example in response to stent implantation) and neoangiogenesis [21]. Endothelial cell migration is regulated by wall shear stress - a mechanical force exerted by flowing blood on the vessel wall [22]. This phenomenon is mediated by a number of chemotactic agents secreted by the endothelium itself as well as by white cells and thrombocytes, and by insulin like grow factors and insulin grow factor binding protein $[23,24]$. Impaired EM has been described in several conditions including insulin resistance [25].

The endothelium is not a homogenous tissue. Endothelial cells derived from different vessels have different properties including gene and protein profile expression, which results in differential functions depending on vessel of origin $[26$,
27]. Abnormal function of coronary arteries can affect the outcomes of medical, surgical, and catheter-based intervention, predispose to cardiac events, and increase cardiovascular morbidity and mortality. Apparently, part of this phenomenon may be explained by endothelial dysfunction which has been repeatedly documented in coronary artery disease (CAD) patients [28].

The aim of our study was to test the hypothesis that OSA induces serum factors affecting coronary artery endothelial cell migration.

\section{Material and methods}

We studied 24 subjects: 12 healthy controls and 12 patients with newly-diagnosed, never-treated severe OSA. All subjects were non-smokers. OSA patients were free from any other chronic diseases including hypertension, and diabetes, and were taking no medications. Both groups were matched for age, body mass index (BMI) and gender (Table I).

Study protocol: All subjects underwent full polysomnography. Blood was collected at three time points, before sleep (at 21:00, $4 \mathrm{~h}$ after last meal), immediately after waking from sleep (at 6:00), and $5 \mathrm{~h}$ after waking (at 11:00), after a standardized breakfast. Serum was immediately isolated, protected with protease inhibitors and frozen at $-80^{\circ} \mathrm{C}$. Written informed consent was obtained from all subjects. The study was approved by the Institutional Human Subjects Review Committee.

Human coronary artery endothelial cells (HCAEC) were grown in EBM-2 media supplemented with growth factors and 2\% fetal bovine albumin (Cambrex, USA). Experiments were conducted using cells after 3 passages at $80-90 \%$ confluency. Experiments were performed using a QCMTM 24 well colometric cell migration kit according to the manufacturer's instructions (Chemicon, USA). Cells $\left(1 \times 10^{5}\right)$ in $300 \mu \mathrm{l}$ serum-free medium were added to the upper chambers and cultured for $24 \mathrm{~h}$. Lower chamber medium was enriched with $2 \%$ study

Table I. Anthropometrics and sleep profiles

\begin{tabular}{|c|c|c|c|}
\hline Variable & Controls $(N=12)$ & OSA $(N=12)$ & Value of $p$ \\
\hline Age [years] & $37.2 \pm 5.6$ & $38.9 \pm 9.7$ & NS \\
\hline BMI $\left[\mathrm{kg} / \mathrm{m}^{2}\right]$ & $30.5 \pm 4.5$ & $32.9 \pm 5.8$ & NS \\
\hline Male/female, $n$ & $7 / 5$ & $7 / 5$ & NS \\
\hline Baseline $\mathrm{SpO}_{2}(\%)$ & $97.2 \pm 0.7$ & $97.5 \pm 1.1$ & NS \\
\hline $\mathrm{AHI}[$ events/h] & $0.9 \pm 0.6$ & $45.3 \pm 19.5$ & $<0.0001$ \\
\hline Mean nocturnal $\mathrm{SpO}_{2}(\%)$ & $96.6 \pm 1.1$ & $92.8 \pm 2.1$ & $<0.05$ \\
\hline Lowest nocturnal $\mathrm{SpO}_{2}(\%)$ & $90.5 \pm 4.2$ & $69.5 \pm 21.1$ & $<0.001$ \\
\hline$\%$ of sleep time with $\mathrm{SpO}_{2}>90 \%$ & $99.1 \pm 0.2$ & $90.2 \pm 9.2$ & $<0.05$ \\
\hline
\end{tabular}

Data presented as mean values $\pm S D$. P-values for unpaired t-tests. $B M I-$ body mass index, $S p \mathrm{O}_{2}-$ blood oxygen saturation, $A H I-a p n e a l$ hypopnea index. 
subjects' serum (chemo-attractant). Non-migrating cells were removed with cottons swabs. Cells that migrated to the bottom of the membrane were lysed and stained with the stain buffer provided in the assay kit. Absorbance measured at the length of $650 \mathrm{~nm}$ of the cell lysis solution was a function of cell migration and was defined as HCAEC migration ability. The study was repeated three times using different HCAEC donors.

\section{Statistical analysis}

The differences between the groups were assessed using Student's $t$-Test and analysis of variance (ANOVA) for repeated measures.

\section{Results}

The characteristics of the study subjects are presented in Table I.

Results are shown in Figure 1. Human coronary artery endothelial cells showed differential migration effects in response to exposure to serum obtained from healthy subjects at three time-points. We observed increased cell migration in cells exposed to early morning serum from healthy subjects (Figure 1). In controls, the highest migration rate was present at 6:00 - after waking from sleep. It decreased at 11:00, returning to the level similar to the evening baseline.

Serum obtained from OSA subjects had a blunted ability to stimulate endothelial cell migration ( $p=0.02$ vs. controls at 21:00). Furthermore, the EM morning increase in endothelial migration observed in healthy controls was attenuated in cells exposed to serum obtained from OSA subjects ( $p<0.001$ vs. controls at 6:00), which showed a flat pattern throughout all time-points.

\section{Discussion}

We report, for the first time, that serum collected from healthy subjects at three different time points exerts time-dependent chemo-attractant effects on human coronary endothelial cells. The peak chemo-attraction occurs after arousal in the morning hours, and might reflect the circadian pattern of coronary artery endothelial cell migration. This pattern is disrupted in severe sleep apnea, where chemo-attractant properties of serum from patients with OSA is weaker, and no morning increase is observed. Our findings might help explain the difference of diurnal profiles of cardiovascular events between the general population and OSA subjects, in whom there is an increased cardiovascular risk during the nighttime hours.

Both OSA and cardiovascular disease have been linked to altered diurnal profiles of numerous agents potentially influencing endothelial cell migration, proliferation and vascular tone [9,
29, 30]. However, comprehensive assessment of their role is challenging due to their in vivo interactions. Most previous studies evaluated endothelial function by measurement of vasodilating ability. Diurnal variation of endothelial function is disturbed in coronary artery disease patients [31]. Flow mediated vasodilation has been reported to be reduced in the morning hours in variant angina patients, and it was associated with a higher number of ischemic incidents in this group [32]. However, none of the previous studies assessed diurnal changes of cell proliferation or migration.

Our study supports the concept that healthy sleep is important for proper coronary endothelial cell migration, and hence regeneration and intimal self-healing. We were not able to observe any morning increase of HCAEC migration ability in the presence of OSA serum. This loss of the normal diurnal profile might be explained by several factors including humoral effects of recurrent hypoxia, inflammation, or increased sympathetic activity. Our findings may have important clinical implications. In untreated OSA patients, recurrent chronic nightly attenuation of HCAEC migration a mechanism of endothelial repair may contribute to endothelial dysfunction, and hence acceleration of atherosclerosis. These data might be of particular relevance in patients undergoing coronary artery interventions such as balloon angioplasty and stent implantation. Patients with OSA

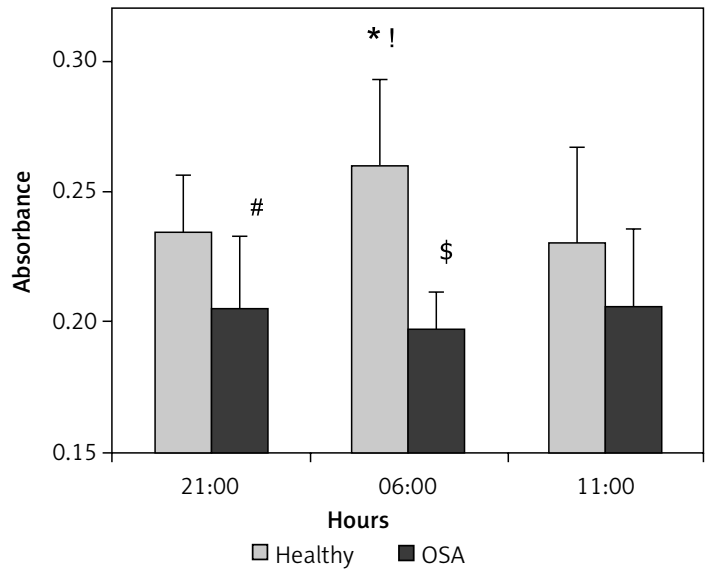

Figure 1. Endothelial cell migration (ECM) in response to serum obtained from healthy controls $(n=12)$ and OSA subjects $(n=12)$. The ECM in response to serum obtained from healthy individuals shows a diurnal profile with a peak of absorbance measured at 6:00 ( ${ }^{*} p=0.02$ vs. $21: 00$, and $p=0.03$ vs. $11: 00)$. This pattern was disrupted in OSA patients, in whom chemo-attractant activity was weaker than in normal controls at 21:00 ( ${ }^{\#} p=$ $0.02)$ and at $6: 00\left({ }^{\$} p<0.001\right)$, and did not change significantly at the different time-points $(p<0.001$ OSA vs. controls)

Data are presented as mean values (bars) with SD (whiskers). T-tests for direct comparisons and ANOVA with repeated measurements for time-related assessment. 
have increased cardiovascular risk after coronary intervention [33].

However, we cannot rule out that inhibition of migration of HCAEC in response to OSA serum could potentially be a protective mechanism. Cell migration is an energy consuming process and engages large transcript activity. Repetitive hypoxemia-reoxygenation might be harmful for cells during apneic episodes. We have previously reported potentially beneficial responses protecting the most vulnerable phase of the cell cycle from the stresses associated with apnea and hypoxemia $[34,35]$. Transcript levels of genes which promote cell division/proliferation are decreased and gene transcripts known to attenuate the cell cycle are increased after overnight apneic sleep [34]. Sleep apnea induces activation of one of the major inhibitors of mitogen activated protein kinases (MAPK) - DUSP1 and its link with MnSOD induction suggest the presence of protective mechanisms in sleep apnea [35]. Results of the present study, taken together with our earlier findings, suggest that the observed phenomenon of arresting/attenuating cell migration might decrease the exposure of the cells to excessive stress and seek to prevent long term cardiovascular damage.

Potential limitations of our study include the relatively small number of patients. However, this is mitigated by several strengths, which include the following: (1) patients had severe OSA and were newly diagnosed and untreated; (2) they were free of other diseases; and (3) control subjects and patients with OSA were matched for body mass in dex, age, and sex, thus ruling out any potential confounding influence of these variables on our data.

Whether CPAP treatment restores the normal diurnal profile of human coronary endothelial cell migration ability in OSA patients remains to be elucidated in future studies.

In conclusion, based on our results we conclude that serum obtained from obstructive sleep apnea patients impairs human coronary endothelial cell migration. Altered chemo-attractant serum activity may conceivably contribute to the disarrangement of endothelial function, commonly documented both in coronary artery disease and obstructive sleep apnea patients.

\section{Conflict of interest}

Virend K. Somers is supported by National Institutes of Health (NIH HL65176).

Prachi Singh is supported by American Heart Association Scientist Development Grant 11SDG7 260046.

\section{References}

1. Cooke-Ariel H. Circadian variations in cardiovascular function and their relation to the occurrence and tim- ing of cardiac events. Am J Health Syst Pharm 1998; 55 Suppl. 3: S5-11.

2. Somers VK, Dyken ME, Mark AL, Abboud FM. Sympathetic-nerve activity during sleep in normal subjects. N Engl J Med 1993; 328: 303-7.

3. Tofler GH, Brezinski D, Schafer Al, et al. Concurrent morning increase in platelet aggregability and the risk of myocardial infarction and sudden cardiac death. N Engl J Med 1987; 316: 1514-8.

4. Elherik K, Khan F, McLaren M, Kennedy G, Belch JJ. Circadian variation in vascular tone and endothelial cell function in normal males. Clin Sci (Lond) 2002; 102: 547-52.

5. Otto ME, Svatikova A, Barretto RB, et al. Early morning attenuation of endothelial function in healthy humans. Circulation 2004; 109: 2507-10.

6. Ma A, Pan X, Xing Y, Wu M, Wang Y, Ma C. Elevation of serum CXCL16 level correlates well with atherosclerotic ischemic stroke. Arch Med Sci 2014; 10: 47-52.

7. Murray KN, Girard S, Holmes WM, et al. Systemic inflammation impairs tissue reperfusion through endothelin-dependent mechanisms in cerebral ischemia. Stroke 2014; 45: 3412-9.

8. Brevetti G, Giugliano G, Brevetti L, Hiatt WR. Inflammation in peripheral artery disease. Circulation 2010; 122: 1862-75.

9. Ohga E, Nagase T, Tomita T, et al. Increased levels of circulating ICAM-1, VCAM-1, and L-selectin in obstructive sleep apnea syndrome. J Appl Physiol (1985) 1999; 87: 10-4.

10. Shamsuzzaman AS, Winnicki M, Lanfranchi P, et al. Elevated C-reactive protein in patients with obstructive sleep apnea. Circulation 2002; 105: 2462-4.

11. Schiza SE, Simantirakis E, Bouloukaki I, et al. Sleep patterns in patients with acute coronary syndromes. Sleep Med 2010; 11: 149-53.

12. Barcelo A, Miralles C, Barbe F, Vila M, Pons S, Agusti AG. Abnormal lipid peroxidation in patients with sleep apnoea. Eur Respir J 2000; 16: 644-7.

13. Lavie L, Vishnevsky A, Lavie P. Evidence for lipid peroxidation in obstructive sleep apnea. Sleep 2004; 27 : 123-8.

14. Muller JE, Stone PH, Turi ZG, et al. Circadian variation in the frequency of onset of acute myocardial infarction. N Engl J Med 1985; 313: 1315-22.

15. Argentino C, Toni D, Rasura M, et al. Circadian variation in the frequency of ischemic stroke. Stroke 1990; 21: 387-9.

16. Gami AS, Howard DE, Olson EJ, Somers VK. Day-night pattern of sudden death in obstructive sleep apnea. N Engl J Med 2005; 352: 1206-14.

17. Hoyos CM, Melehan KL, Liu PY, Grunstein RR, Phillips CL. Does obstructive sleep apnea cause endothelial dysfunction? A critical review of the literature. Sleep Med Rev 2015; 20: 15-26.

18. Vgontzas AN, Papanicolaou DA, Bixler EO, et al. Sleep apnea and daytime sleepiness and fatigue: relation to visceral obesity, insulin resistance, and hypercytokinemia. J Clin Endocrinol Metab 2000; 85: 1151-8.

19. Bruno RM, Rossi L, Fabbrini M, et al. Renal vasodilating capacity and endothelial function are impaired in patients with obstructive sleep apnea syndrome and no traditional cardiovascular risk factors. J Hypertens 2013; 31: 1456-64.

20. Hashimoto $M$, Akishita $M$, Eto $M$, et al. The impairment of flow-mediated vasodilatation in obese men with visceral fat accumulation. Int J Obes Relat Metab Disord 1998; 22: 477-84. 
21. Lauffenburger DA, Horwitz AF. Cell migration: a physically integrated molecular process. Cell 1996; 84: 359-69.

22. Albuquerque ML, Waters CM, Savla U, Schnaper HW, Flozak AS. Shear stress enhances human endothelial cell wound closure in vitro. Am J Physiol Heart Circ Physiol 2000; 279: H293-302.

23. Yuldasheva NY, Rashid ST, Haywood NJ, et al. Haploinsufficiency of the insulin-like growth factor-1 receptor enhances endothelial repair and favorably modifies angiogenic progenitor cell phenotype. Arterioscler Thromb Vasc Biol 2014; 34: 2051-8.

24. Bach LA. Endothelial cells and the IGF system. J Mol Endocrinol 2015; 54: R1-13.

25. Kahn MB, Yuldasheva NY, Cubbon RM, et al. Insulin resistance impairs circulating angiogenic progenitor cell function and delays endothelial regeneration. Diabetes 2011; 60: 1295-303.

26. Nolan DJ, Ginsberg M, Israely E, et al. Molecular signatures of tissue-specific microvascular endothelial cell heterogeneity in organ maintenance and regeneration. Dev Cell 2013; 26: 204-19.

27. Belloni PN, Tressler RJ. Microvascular endothelial cell heterogeneity: interactions with leukocytes and tumor cells. Cancer Metastasis Rev 1990; 8: 353-89.

28. Goch A, Banach M, Mikhailidis DP, Rysz J, Goch JH. Endothelial dysfunction in patients with noncomplicated and complicated hypertension. Clin Exp Hypertens 2009; 31: 20-30.

29. Ohga E, Tomita T, Wada H, Yamamoto H, Nagase T, Ouchi Y. Effects of obstructive sleep apnea on circulating ICAM-1, IL-8, and MCP-1. J Appl Physiol (1985) 2003; 94: 179-84.

30. Vgontzas AN, Papanicolaou DA, Bixler EO, et al. Circadian interleukin-6 secretion and quantity and depth of sleep. J Clin Endocrinol Metab 1999; 84: 2603-7.

31. Shaw JA, Chin-Dusting JP, Kingwell BA, Dart AM. Diurnal variation in endothelium-dependent vasodilatation is not apparent in coronary artery disease. Circulation 2001; 103: 806-12.

32. Kawano H, Motoyama T, Yasue $\mathrm{H}$, et al. Endothelial function fluctuates with diurnal variation in the frequency of ischemic episodes in patients with variant angina. J Am Coll Cardiol 2002; 40: 266-70.

33. Wu X, Lv S, Yu X, Yao L, Mokhlesi B, Wei Y. Treatment of OSA reduces the risk of repeat revascularization after percutaneous coronary intervention. Chest 2015; 147: 708-18.

34. Hoffmann MS, Singh P, Wolk R, Romero-Corral A, Raghavakaimal S, Somers VK. Microarray studies of genomic oxidative stress and cell cycle responses in obstructive sleep apnea. Antioxid Redox Signal 2007; 9: 661-9.

35. Hoffmann MS, Singh P, Wolk R, Narkiewicz K, Somers VK. Obstructive sleep apnea and intermittent hypoxia increase expression of dual specificity phosphatase 1 . Atherosclerosis 2013; 231: 378-83. 